\title{
A Case Study of Pachyonychia Congenita in Bangladesh
}

\author{
Zahed Parvez and Samina Akter
}

\section{ABSTRACT}

In 1906 Jadassohn and Lewandowsky described a rare genodermatoses and named it pachyonychia congenita. Pachy means thick. It is a group of genodermatoses involving keratin mutation with thickened nails and variable associated findings. Pachyonychia congenita is a rare disease having four types. However, type 1 and type 2 can be considered common among them. It can often mimic with fungal infection as nail hyperkeratosis can occur in both.

Keywords: Hyperkeratosis, Mutation, Pachyonychia congenita, Rare.
Submitted : April 20, 2021

Published : May 11, 2021

ISSN: 2593-8339

DOI: $10.24018 /$ ejmed.2021.3.3.822

Dr. Zahed Parvez

MBBS (DU), BCS (Health), MPH (BSMMU), DDV (DU),

Trained in Cosmetic \& Hair Transplant Surgery, India.

Consultant \& Cosmetic Surgeon, Assistant Professor, Shaheed Suhrawardy Medical College \& Hospital, Dhaka, Bangladesh.

(e-mail: zahedparvezmmc@ gmail.com)

Dr. Samina Akter*

Medical Officer, Dr. Zahed's Hair \&

Skinic, Panthapath, Dhaka,

Bangladesh.

(email: samina.mithila123@gmail.com)

*Corresponding Author

\section{CASE REPORT}

A 20-year-old patient came to our institute with grossly thickened nail plates associated with thickening of skin on pressure points. He has this problem by birth and started taking treatment locally at the age of 10 . He was referred to the tertiary center as there was no improvement by the treatment from GP. Therefore, he came to our institution and we observe the case thoroughly and did possible investigation to rule out other disease and came to a conclusion with the diagnosis of Pachyonychia congenita Type1. Diagnosis is made mainly on the basis of clinical findings. Patient previously had significant oral leukoplakia which was later healed leaving a characteristic yellow lesion.

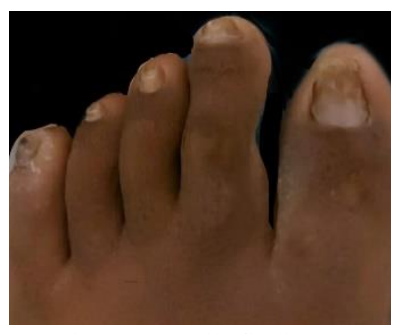

Fig. 1. Toenails finding.

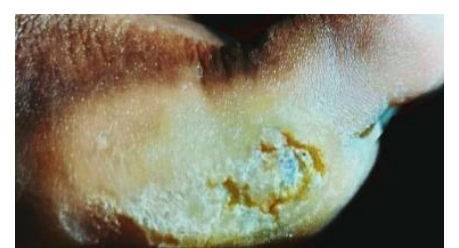

Fig. 2. Plantar lesion. 


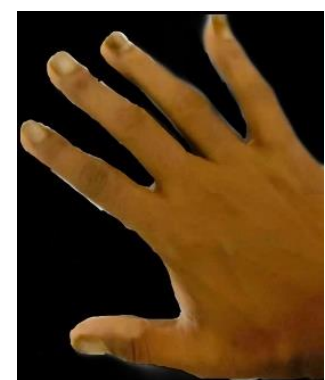

Fig. 3. Fingernails finding of right hand.

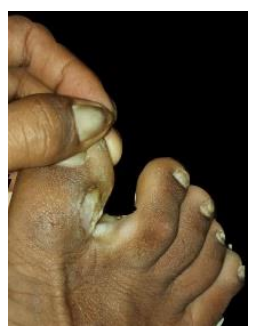

Fig. 5. Lesion on the inter digital space of right foot.

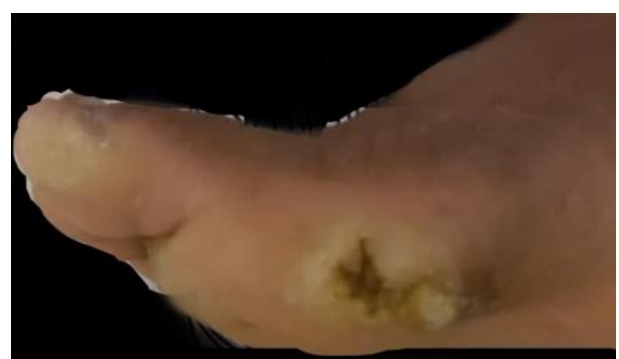

Fig. 7. Plantar lesion.

\section{DISCUSSION}

Among many classifications schemes the major similarities appear to be the diagnostic significance of corneal dystrophy, presence of natal teeth and multiple cysts and absence of oral leukoplakia [4]. In our case which we studied at first fingernails and toenails became thickened, friable, and darkened. Distal involvement of the thumbs and index fingers tend to be more severely involved. Nails were shed and new nails were also dystrophic. There was occasional blistering of soles. As the course of the disease is chronic and involves palmoplantar keratoses and nail changes it interferes with patient's quality of life.

Congenital abnormality of the nail can occur as an isolated nail change or be a part of syndrome [4]. In this case it was an isolated nail abnormality. To confirm the diagnosis Histopathology was done which shown the nail plate and proximal nail matrix. The nail bed showed marked hyperkeratosis. The distal nail matrix is hypertrophic. There was some disagreement of microscopic features.

Patient was primarily given symptomatic treatment. Emollients and keratolytic were used for hyperkeratosis. Routine grinding of the nail plates to keep their interference with function at a minimum was done. But the nail remains cosmetically dystrophic.

\section{CONCLUSION}

We acknowledge the limitation of this study and believe that additional studies are needed with more patient for proper understanding of the pattern of the disease.

\section{REFERENCES}

[1] Acta Derm Venereol, 55 (1975), pp. 387-394.

[2] A letter from Mr St. George Ash, Sec. of the Dublin Society, to one of the Secretaries of the Royal Society: Concerning a girl in Ireland, who has several horns growing on her body. Phil Trans R1 Soc London, 15 (1685), pp. 1202-1204

[3] Benjamin et al., 1987. B. Benjamin, D.S. Parsons, H.F. Molloy, Pachyonychia congenita with laryngeal involvement, Int J Pediatr Otorhinolaryngol, 13 (1987), pp. 205-209.

[4] J. Bondeson, Pachyonychia congenita. A historical note, Am J Dermatopathol, 15 (1993), pp. 594-599.

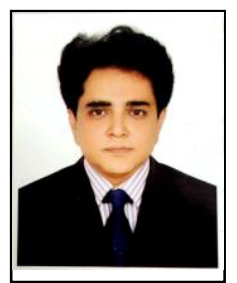

Dr. Zahed Parvez is a renowned Professor of Shaheed Suhrawardy Medical College \& Hospital, Dhaka, Bangladesh. He is the pioneer of Hair Transplantation Surgery in Bangladesh. He completed his MBBS degree from Mymensingh Medical College, Bangladesh. He is practicing dermatology since 2003 .

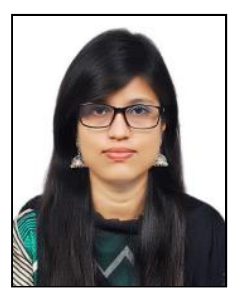

Dr. Samina Akter is currently working as a Medical Officer at Dr. Zahed's Hair \& Skinic, Panthapath, Dhaka, Bangladesh. Her research focus is in the area of public health, contagious diseases, etc. She holds an MBBS degree from Kumudini Women's Medical College, Tangail, Bangladesh. 